\title{
Farmacoeconomia e farmacoepidemiologia na gestão de recursos em saúde: primeiros resultados de uma revisão integrativa
}

\author{
Ellen Cristina Alves de PAULA ${ }^{(1)}$ \\ Samara Jamile MENDES(1) \\ ${ }^{(1)}$ Faculdade de Saúde Pública, Universidade de São Paulo - USP, São Paulo, SP, Brasil.
}

Recebido: 28 jan 2019 Aceito: 10 fev 2019

Autor de correspondência: 13ellen@gmail.com

Conflito de interesses: Os autores declaram não haver nenhum interesse profissional ou pessoal que possa gerar conflito de interesses em relação a este manuscrito.

\section{Resumo}

A farmacoeconomia é a junção da descrição e análise comparativa dos custos com os desfechos terapêuticos de um tratamento medicamentoso, produto em saúde ou serviço em saúde, visando a otimização de recursos financeiros, sem prejudicar a qualidade de vida e o tratamento ao paciente. Tem como definição segundo a diretriz metodológica do ministério da saúde sobre avaliações econômicas de tecnologias em saúde: "[...] Conjunto de atividades dedicadas, de modo geral, à análise econômica no campo da Assistência Farmacêutica, como a gestão de serviços farmacêuticos, a avaliação da prática profissional e a avaliação econômica de medicamento e, de modo específico, à descrição e à análise dos custos e das consequências da farmacoterapia para o paciente, o sistema de saúde e a sociedade [...]". Em países subdesenvolvidos e/ou em desenvolvimento, como é o caso do Brasil, há recursos limitados para implementação de novas tecnologias, sendo assim, o uso da farmacoeconomia se torna um fator muito importante pois permite reduzir custos garantindo a utilização de um serviço com qualidade, podendo também contribuir com o uso racional de medicamentos. As avaliações farmacoeconômicas mais antigas utilizavam apenas critérios de eficácia e segurança, porém com o aumento dos custos e das restrições orçamentárias dos sistemas de saúde, se fez necessário adotar alguns critérios não somente clínicos e de segurança como também econômicos e de dados pós comercialização do produto, como a farmacovigilância, que subsidiem a tomada de decisão a respeito da incorporação/inclusão racional de novas tecnologias. Este tipo de análise passou a ser denominada Avaliação de Tecnologias em Saúde - ATS. Os dados farmacoepidemiológicos, principalmente os de farmacovigilância, estão incorporados nos estudos farmacoeconômicos, e a sua utilização garante o melhor aproveitamento dos tratamentos avaliados assim como dos recursos disponíveis, visando sempre a assistência com qualidade, dos pacientes. Os estudos de reações adversas a medicamentos na farmacoeconomia sugerem que os governos gastam quantias consideráveis do orçamento com o manejo desses eventos que poderiam ter sido evitados com trabalhos de prevenção. Segundo as Diretrizes Nacionais para a Vigilância de eventos adversos e queixas técnicas de produtos sob Vigilância Sanitária de 2005, foram registradas cerca de 21.500 internações (59 internações/dia) devidas a problemas associados ao uso de medicamentos (PRM), totalizando um custo aproximado de oito milhões e trezentos mil reais ( $\mathrm{R} \$ 8.300 .000,00)$. Em relação a mortalidade, o 
Sistema de Informação sobre Mortalidade - SIM, do Ministério da Saúde informa a ocorrência de 6 mil mortes entre o período de 1996-2003. Objetivo: sabendo da importância dos dados farmacoepidemiológicos (farmacoepidemiologia e farmacovigilância) nas análises farmacoeconômicas, este estudo teve como objetivo identificar estudos farmacoeconômicos com ênfase na farmacoepidemiologia, (custo-efetividade, custo-benefício, ou custo utilidade) a fim de conhecer como os principais resultados poderiam ser empregados na gestão de recursos no sistema de saúde. Método: a pesquisa é uma revisão da literatura do tipo integrativa que bem como as demais revisões literárias, são pesquisas que utilizam como fonte de dados a literatura sobre determinado tema. Esse tipo de investigação disponibiliza um resumo das evidências relacionadas a uma estratégia específica, mediante a aplicação de métodos explícitos e sistematizados de busca como pergunta estrutural, revisores, apreciação crítica e síntese das informações selecionadas. As revisões integrativas são úteis para integrar as informações de um conjunto de estudos realizados separadamente sobre determinada intervenção, que possam apresentar resultados conflitantes e/ou coincidentes, bem como identificar temas que necessitam de evidência, auxiliando na orientação para investigações futuras. Sabendo disso foi realizado uma revisão sistemática integrativa que visa analisar as melhores evidências científicas disponíveis sobre estudos farmacoeconômicos em farmacovigilância e sua utilização na gestão em saúde. A busca sistematizada foi realizada na plataforma do Portal Regional da BVS (http://bvsalud.org/), partindo-se da técnica de funil, combinando-se diversos descritores relacionados ao tema e utilizando-se as sintaxes necessárias para refinar a busca. A composição sintática realizada do tema parte da compreensão de cinco polos temáticos de interesse, identificados a partir da pergunta da pesquisa: (a) farmacoeconomia; (b) farmacoepidemiologia; (c) avaliação de tecnologias biomédicas; (d) Gestão de Recursos; e (e) Custos e Análise de Custo. Resultados: a revisão integrativa de literatura selecionou nove artigos no período de dezembro de 2018, publicados em inglês, português e ou espanhol. Devido à escassez de recursos na área da saúde, aliado ao aumento do envelhecimento populacional, o uso da farmacoeconomia tem se tornado uma excelente ferramenta para a tomada de decisão quanto aos recursos em saúde disponibilizados. Apesar disso ainda foi possível identificar, nos estudos de reações adversas a medicamentos na farmacoeconomia, que os governos gastam quantias consideráveis do orçamento com o manejo desses eventos que poderiam ter sido evitados com trabalhos de prevenção e acompanhamentos periódicos. Considerações finais: a revisão sistemática integrativa demonstrou que o uso da farmacoeconomia no sistema de saúde já está sendo utilizado, mas que são necessários investimentos para sua melhor utilização, visando sempre uma melhor gestão de recursos disponíveis e com uma melhor qualidade no serviço ou material em saúde prestado.

Descritores: Farmacoeconomia; Farmacoepidemiologia; Custos e análise de custos; Gestão de recursos; Tecnologias biomédicas. 